\title{
Ultra-Microtomy by a New Method
}

\author{
By Sanford B. Newman, Emil Borysko, and Max Swerdlow
}

\begin{abstract}
Polymerization of $n$-butyl methacrylate monomer is used as a rapid and simple means for embedding fixed biological material. The solid resin provides an optically clear matrix for cutting very thin sections, one at a time, with a slightly modified conventional rotary microtome. Advance of the embedded specimen toward the knife is obtained from the thermal expansion of a brass specimen holder. These ultrathin sections have uniform thickness, large area, and integrity of tissue structure. They are suitable for producing transmission images at the higher magnifications of the conventional light, phase-contrast, and electron microscopes. Metallic shadowing of the sections provides greater contrast as well as a threedimensional aspect to the structural details of the tissue. Micrographs and a bibliography are presented.
\end{abstract}

\section{Introduction}

With the development of the electron microscope as a tool of science arose the problem of preparing sections of biological materials that would give satisfactory images in the instrument. The penetrating power of the electron beam in commercial microscopes using accelerating potentials of 100 $\mathrm{kv}$ or less is very slight and, because of the great relative depth of field involved, the specimen structure is difficult to interpret when sections are over a fraction of a micron in thickness.

Over the years various solutions to this problem have been described in the literature, but no wholly satisfactory method for sectioning all kinds of material has appeared. It would seem that any single technique is applicable to only a selected group of materials. Cutting wedge-shaped sections and using the thinnest portions for electron microscopy is a technique described by several workers $[1,2,4,5] .{ }^{1}$ The methods used, however, have been laborious and difficult to reproduce. Sjöstrand [8] produced an electron micrograph of skeletal muscle fiber from a thin section. Although details of the sectioning technique are not given, the text indicates that it was probably some variation of the wedge-section method.

\footnotetext{
1 Figures in brackets indicate the literature references at the end of this paper.
}

A more successful approach to the problem was the use of the high-speed microtome $[7,12,13$, $14,15,19,20,21,23,24,25]$, but this equipment, besides being expensive and complex, produces a low percentage of usable sections. Sections are cut so rapidly and abundantly that selection is laborious and uncertain.

The most recent effort has been that of Pease and Baker [26], who have used standard histological techniques to embed a $1-\mathrm{mm}$ cube of tissue in collodion and paraffin. For sectioning, they altered a Spencer rotary microtome so that the unit of advance was reduced to approximately one-tenth of the calibrated value. The microtome was then reported to produce sections as thin as 0.1 micron $[28,29]$.

The need for a practical inexpensive method for cutting uniform thin sections, having adequate area and integrity of structure, is still apparent to those working with commercial transmissiontype electron microscopes. The growing use of the phase-contrast method in optical microscopy has made the problem more acute. This paper describes a method for obtaining ultrathin sections involving the use of methacrylic resins as embedding media, a thermal expansion apparatus for advancing the specimen in a conventional microtome, and metallic shadow-casting for increasing observable detail in the sections. 


\section{Sectioning Procedure}

\section{Embedding Materials}

It is not intended that this description of the materials to be used in producing thin sections shall include formulae of fixing solutions, components of the dehydrating series, or other information available in many histological or cytological texts.

The $n$-butyl methacrylate monomer used for embedding, as purchased, ${ }^{2}$. contains an inhibitor (hydroquinone). This is removed by repeated washings in a separatory funnel with a dilute aqueous solution of sodium carbonate until no color is visible in the washing solution. Calcium chloride is used to remove water from the washed monomer. After the inhibitor is removed, the monomer is kept in a refrigerator to inhibit polymerization. Rubber or plastic materials should not be used for storing the monomer.

A low-temperature catalyst is necessary for use at the polymerization temperature required for this work. With its optimum activation in the temperature range from $40^{\circ}$ to $60^{\circ} \mathrm{C}, 2,4$-dichlorobenzoyl peroxide ${ }^{3}$ has given excellent results, but other catalysts may be as satisfactory. It is best to obtain the catalyst in a pure form, since certain of the plasticizers incorporated in commercial products are insoluble in $n$-buytl methacrylate. To remove insolubles, filtration of the monomer plus catalyst may be necessary.

\section{Specimen Fixation and Dehydration}

Accepted cytological techniques were employed without modification for the fixation and subsequent dehydration of the tissues in an ethyl alcohol series. The tissues were then ready for embedding with the polymer. The specimens embedded did not exceed $8 \mathrm{~mm}^{3}$ in volume. A variety of tissues were fixed in several different preparations to determine the suitability of the techniques for general use.

\section{Embedding Technique}

\section{(a) Encapsulation and Polymerization}

After dehydration in absolute ethyl alcohol, the tissues are transferred to a mixture of equal

\footnotetext{
2 Obtained from Rubber Chemicals Division, Rohm and Haas Co., Philadelphia, $\mathrm{Pa}$.

3 Obtained from Lucidol Division, Novadel-Agene Corp., Buffalo, N. Y.
}

volumes of absolute alcohol and monomeric $n$-butyl methacrylate. After about 1 hour in the alcohol-monomer mixture, the tissue is placed in the monomer (without catalyst) for about an equal period. To ensure removal of the alcohol, the tissues are placed for at least 1 hour in each of two additional changes of monomer.

Gelatin capsules, No. 00, are used as embedding molds. The ordinary pharmaceutical colorless grade is readily available and easiest to manipulate. The main body of the capsule is set upright in a wooden block or other base (fig. 1, A). The capsule is then filled with the monomer containing 1 percent (by weight) of the catalyst, 2,4-dichlorobenzoyl peroxide. The tissue is placed in it with the desired orientation. The lid of the capsule is slipped into place to retard loss by evaporation, and the assembled capsule is placed in an oven at a temperature of $45^{\circ}$ to $50^{\circ} \mathrm{C}$ (fig. $1, \mathrm{~B}$ ). It is extremely important that the capsule be evenly heated over its entire surface. An oven with good air circulation should be used and the filled capsules suspended in it with strips of cellophane tape.

At the end of 6 to 8 hours the monomer is polymerized into a solid matrix. The tissue is, of course, embedded at the bottom of the optically clear plastic. An additional period of several hours at this temperature will ensure complete cure. After polymerization the gelatin capsule may be removed by soaking in water and peeling the softened shell from the resin.

\section{Modification of the Microtome}

In the beginning of this study the Spencer (Model 820) rotary microtome was modified in the manner of Pease and Baker [26]. The angle of the slide plane of the instrument was reduced to onetenth of its original value by fastening a milled and surface-ground steel shim against the slide plane. This, in effect, reduced the cutting calibration to about one-tenth of its value.

By means of this altered instrument a number of usable sections were cut from different specimens embedded in the polymer. However, the microtome thus altered was not entirely satisfactory. Although this instrument has proved its worth in the production of thicker sections, the cutting of fractional-micron sections demands a degree of precision for which it was never designed. 

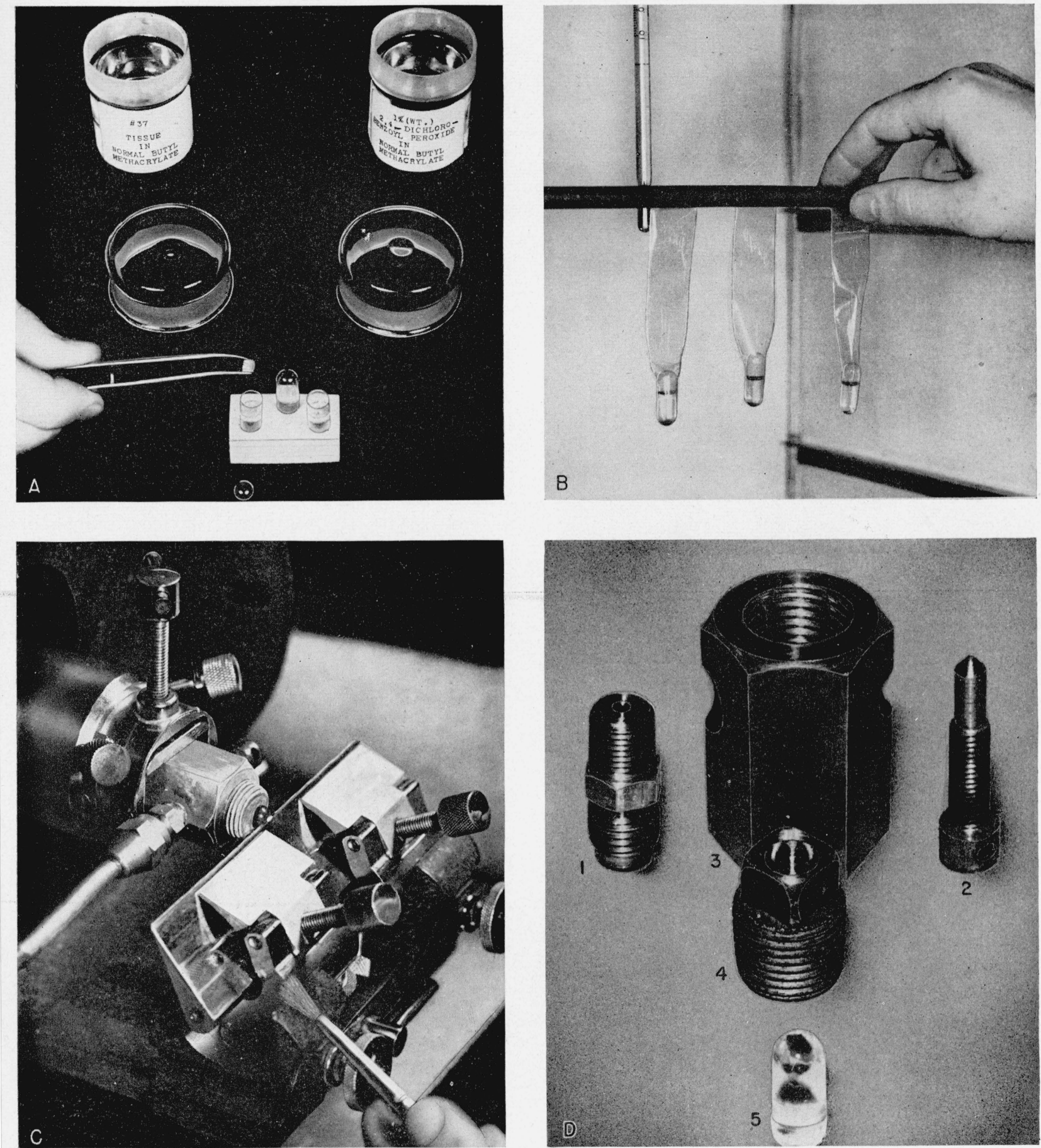

FiguRE 1. Materials and procedures for ultra-microtomy.

$A$, Encapsulation-After fixation and dehydration the tissue, impreg. nated with $n$-butyl methacrylate, is placed in the gelatin capsule containing the monomer to which 1 percent (by weight) of the catalyst, 2,4-dichlorobenzoyl peroxide, has been added.

$C$, Assembled thermal expansion microtome-A section is being cut with the apparatus clamped in the jaws of a commercial microtome. Com. pressed $\mathrm{CO}_{2}$ gas escaping into the expansion chamber cools and contracts the specimen holder. Stopping or reducing the flow of $\mathrm{CO}_{2}$ allows the apparatus to approach room temperature and thus advances the embedded specimen toward the knife.
$B$, Polymerization-The capsules containing tissue and monomer pluo catalyst are closed and suspended in the circulating-air oven at $45^{\circ} \mathrm{t}$ $50^{\circ} \mathrm{C}$ for 6 to $8 \mathrm{hr}$ to polymerize the liquid.

$D$, Disassembled thermal expansion apparatus-(1) and (2) needle valve for $\mathrm{CO}_{2}$ gas; (3) brass expansion chamber tapped for the fittings; (4) standard 3/8-in. brass pipe plug with cavity in face to seat embedded tissue; (5) tissue in the clear resin with gelatin capsule removed. 
To obtain the desired precision, a metallic specimen mount was devised in which the specimen is advanced by means of thermal expansion without modifying the mechanism of the Spencer microtome. The parts for the arrangement are shown in figures 1 and 2 .

The device is essentially a brass block with a hole drilled through the long axis and threaded at

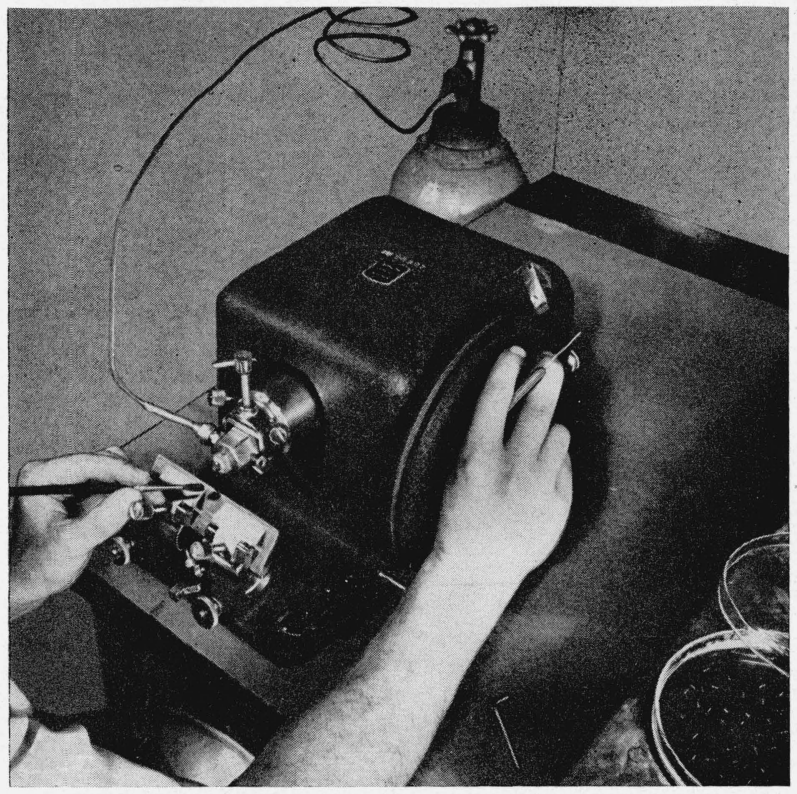

Figure 2. Ultra-microtomy with the thermal expansion instrument.

The tissue embedded in polybutyl methacrylate is seated in the brass specimen holder. Compressed $\mathrm{CO}_{2}$ gas escaping into the expansion chamber behind the specimen cools and contracts the assembly. Stopping or reducing the flow of gas with the needle valve allows the apparatus to approach room temperature and thus provides smooth continuous advance of the embedded tissue toward the knife. The extremely thin sections are lifted from the knife with a dry camel's hair brush. A dissecting needle is used to float the section on a warm water surface.

one end to receive a standard $3 / 8$-in. brass pipe plug, which serves as the specimen mounting block, figure 1, D. A cavity drilled into the face of the plug provides a seat for the embedded specimen. A needle valve situated behind the plug is used to bleed in the coolant, compressed carbon dioxide gas. After cooling, specimen advance toward the knife edge is obtained by allowing the assembly to warm up again. The process involves the continuous thermal expansion of the metallic holder and specimen. This simple device can probably be adapted to any rotary or sliding microtome.

\section{Sectioning the Tissues}

Before placing the mounted and embedded specimen in the microtome clamp, it is sometimes desirable to reduce the area presented to the cutting edge. Sections across the whole body of the capsule have been cut, but these present certain problems in handling; they often fold on themselves, are difficult to flatten, etc. The block containing the embedded material can be held in a lathe and the excess matrix turned down to any desired diameter, or it can simply be trimmed with a sharp knife.

In using the thermal expansion apparatus the embedded specimen is first cemented into the mounting block. To do this, a small amount of a mixture of 1 part of pure gum rubber and 20 parts of paraffin is melted in the cavity by heating the block. The embedded specimen is then pushed into the cavity, and the block is allowed to cool. With the assembled device clamped in the jaws of the microtome head, the needle valve is opened, allowing the compressed carbon dioxide gas to escape into the expansion chamber behind the mounting block. The entire assembly contracts as it is cooled below room temperature. Upon the appearance of a thin layer of frost on the metal, the knife is adjusted so that the specimen just misses it on the cutting stroke. The specimen is then mechanically advanced at 2 - or 3 -micron increments until the first slice is made. The mechanical advancing mechanism is then disengaged by setting it to zero and the gas flow reduced or stopped. After a few seconds the specimen, which is set above the knife edge, can be cut. Because the specimen is advancing continuously, a quick chopping stroke involving one complete revolution of the hand wheel is necessary. With a little experience one can soon judge the necessary time interval between cuts. Some control of the rate of specimen advance can be obtained by bleeding the $\mathrm{CO}_{2}$ at various reduced rates into the expansion chamber. If, however, the temperature is not too far below surroundings, the expansion potential is small and the needle valve can be closed completely. As cutting progresses, the cooling and warming cycle is repeated as necessary.

\section{Selecting and Preparing Sections}

After being cut, the sections usually are somewhat folded. They are lifted from the knife with 
a dry camel's hair brush, picked up with a dissecting needle, and placed on a water surface warmed on a hot plate to about $35^{\circ} \mathrm{C}$, figure 2 . After an interval ranging from a few minutes to an hour or more, many will flatten out on the surface and exhibit bright interference colors. A little wetting agent in the water aids in straightening the sections.

Selected sections are floated onto clean microscope slides and allowed to dry flat. Sections prepared for phase-contrast microscopy are placed in acetone or toluene for about $1 / 2$ hour to remove the matrix and then mounted in Canada Balsam. For ordinary light microscopy, the matrix is dissolved and the sections stained in the usual way. Sections for these uses should be affixed to the slide by means of albumen adhesive.

In preparing material for the electron microscope, the sections are floated from the water onto clean glass slides and dried flat. No adhesive should be used. The matrix is then dissolved from the section by placing the slide in acetone, toluene, or amyl acetate. The moist tissue of the section is left adhering to the glass. A dilute solution of collodion in amyl acetate is flowed over the slide bearing the tissue. Inclining the slide permits discharge of excess collodion. It is then allowed to dry at room temperature. The col-

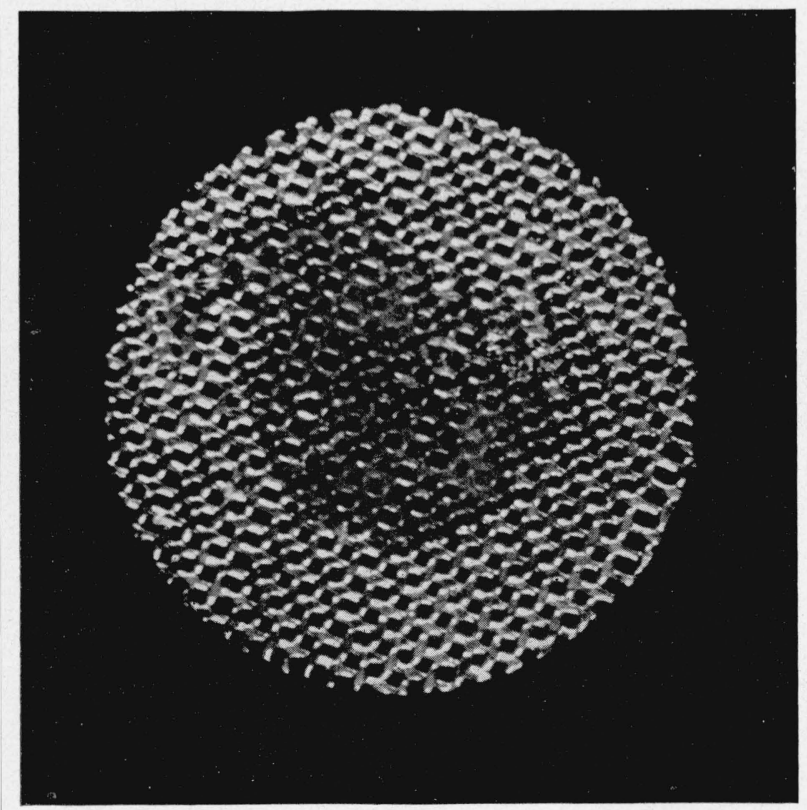

Figure 3. Metal shadowed ultrathin section centered on a $1 / 8$-inch diameter, 200-mesh specimen screen ready for electron microscopy. lodion film containing the sections is floated from the slide onto water. The 1/8-inch, 200-mesh specimen screens are placed over the area of the film containing the section. A 250-watt drying lamp, held about a foot from the film at an angle of about 45 degrees, promotes adhesion of the screen to the film. If the film is floated on a small amount of water on a glass plate, the screens can be more accurately placed with the aid of a binocular microscope. The entire film is then floated from the plate to a larger volume of water, and the freely floating film supporting the specimen screens is removed from the water by flipping it over and out with a glass microscope slide. The screens are thereby lodged between the film and the glass as the film is dried onto the slide. The specimens are then removed for observation or metallic shadowing (fig. 3).

\section{Metallic Shadow-Casting}

Additional contrast as well as a three-dimensional aspect to certain details of the thin section can be obtained by metallic shadow-casting as described by Williams and Wyckoff [10]. Further details of the specific technique used here are given by Swerdlow and Seeman [27]. The legends under the figures give additional data for the shadowed thin sections. The shadowed sections could, of course, be used for light and phasecontrast as well as electron microscopy.

The sections are freed of the embedding medium and stripped from the glass slide with a collodion film as described previously. The sections are then mounted (tissue side up) on the screens and shadowed. This is the easier method of shadowing specimens for electron microscopy, that is, with the material lying above the substrate film. However, if the preshadowing techniques of Williams and Wyckoff $[11,16]$ and Williams and Backus [31] with their relative advantages and difficulties are to be used, the shadow-casting is done immediately after removal of the embedding polymer. Then the section is stripped from the glass slide along with the very thin layer of metal by the usual transfer and mounting methods.

Figures 5 to 14 illustrate the results obtained with the various techniques described. The RCA-EMU $(50 \mathrm{kv})$ eleetron microscope was used for this work. 


\section{Discussion}

The techniques presented here have given satisfactory results. However, a few rigid limitations in several of the steps in the procedure must be considered.

Knife sharpness is of vital importance. However, the microtome cutting edges used were maintained with two different commercial knife sharpeners. The tilt of the knife during sectioning was not particularly critical, no more so than in sectioning for optical microscopy $[6,9]$.

The greatest chance for failure appears to lie in the polymerization of the embedding mass. Use of low-temperature catalysts and a polymerization temperature of $45^{\circ}$ to $50^{\circ} \mathrm{C}$ will usually prevent the formation of resins that are not readily soluble, cause distortion of tissue by swelling and wrinkling, and have inferior cutting qualities. Catalysts, such as benzoyl peroxide, with higher activation temperatures should be avoided. Bubbles may form in the embedding matrix, but their presence is usually not a bar to the successful sectioning of the embedding mass. Occasionally tissues are injured during the polymerization reaction, and such tissues, which are easily detected, can be promptly discarded. The mechanism of injury is not clearly understood, but delicate tissues and unhardened tissues are more often affected. For this reason, the use of fixing solutions with good hardening properties is recommended. The addition of small quantities (10 to $20 \%$ by volume) of methyl methacrylate monomer to the $n$-butyl methacrylate has been tried and yields a harder resin with somewhat better cutting properties but increases the probability of tissue injury.

Methacrylic polymers have poor resistance to electron bombardment even at low beam intensities. For this reason the matrix polymer has been dissolved out of the section. An electron micrograph of a shadowed section of the polymerized matrix (fig. 4) fails to reveal any particulate forms. Fullam and Gessler [13] showed a micrograph of a section of laboratory-polymerized methyl methacrylate containing numerous discrete bodies. Such material does not appear in the plastic used here.

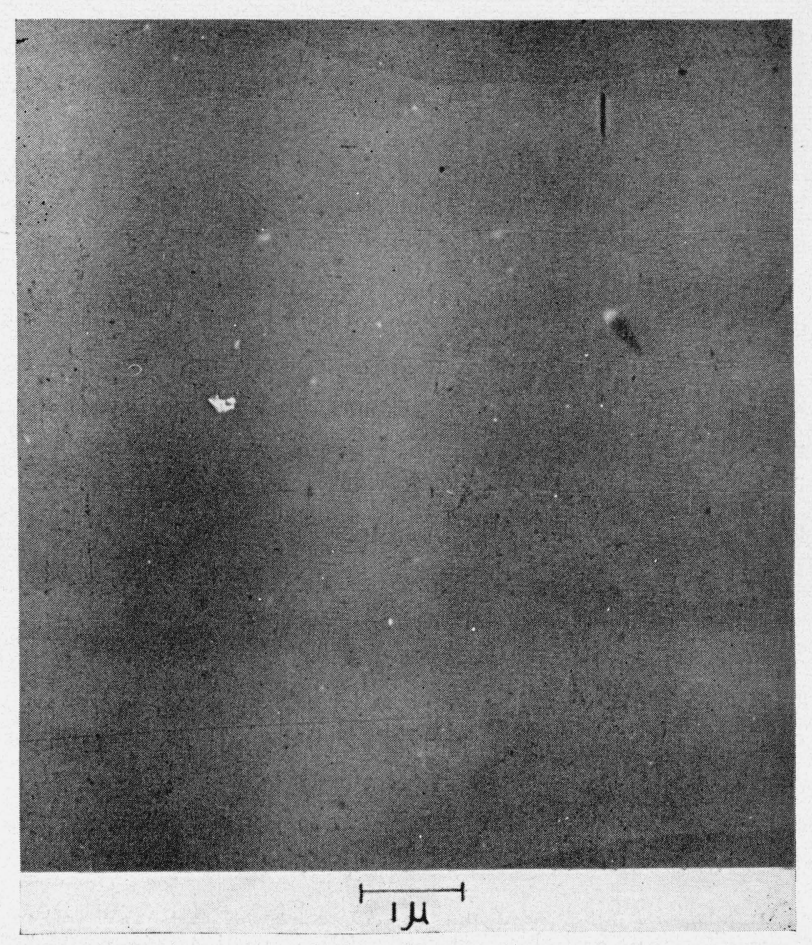

Figure 4. Embedding polymer, section, chromiumshadowed $(4: 1)$.

Electron micrograph, total magnification $\approx \times 10,400$ (electronic $\times 5,200$, optical $\times 2$ ).

The materials sectioned by this method thus far have been plant and animal tissues. The ability to produce sections for study in the electron microscope in anything approaching a routine fashion would be of immense advantage to research in almost any field of biology or medicine concerned with the microstructure of such material. Although fixation artifacts remain problems for serious consideration, the new method presented here provides a practical inexpensive approach to the problem of producing extremely thin sections that have uniform thickness, large area, and integrity of tissue structure.

The authors sincerely appreciate the valuable assistance and helpful suggestions of Elmer A. Koerner, Howard F. McMurdie, and Barbara M. Sullivan in the course of this work. 


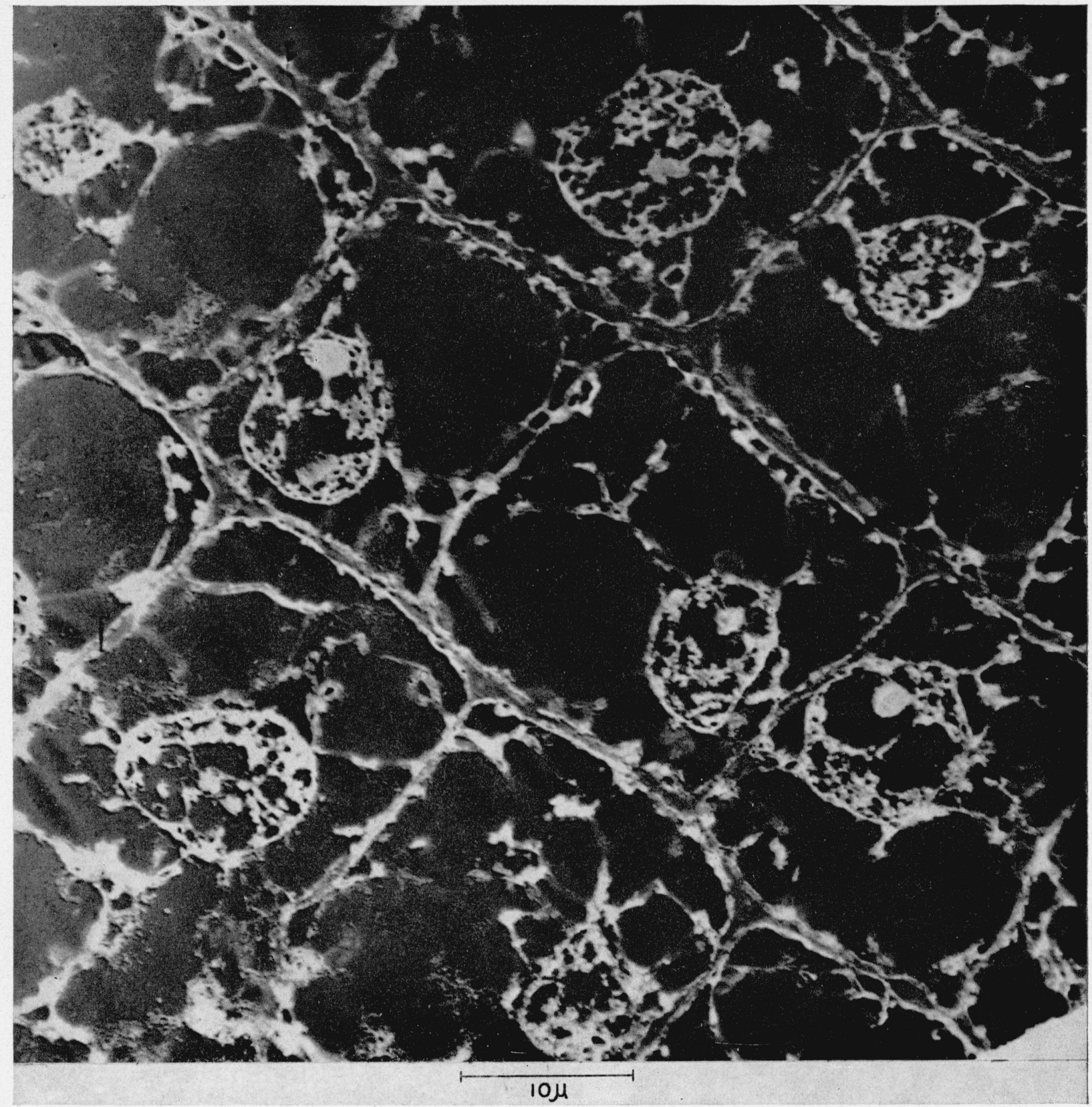

Figure 5. Onion root tip, elongating cells, fixed in medium chrom-acetic, chromium-shadowed (4:1). Electron micrograph, total magnification $\approx \times 2,600$ (electronic $\times 750$, optical $\times 3.5$ ). 

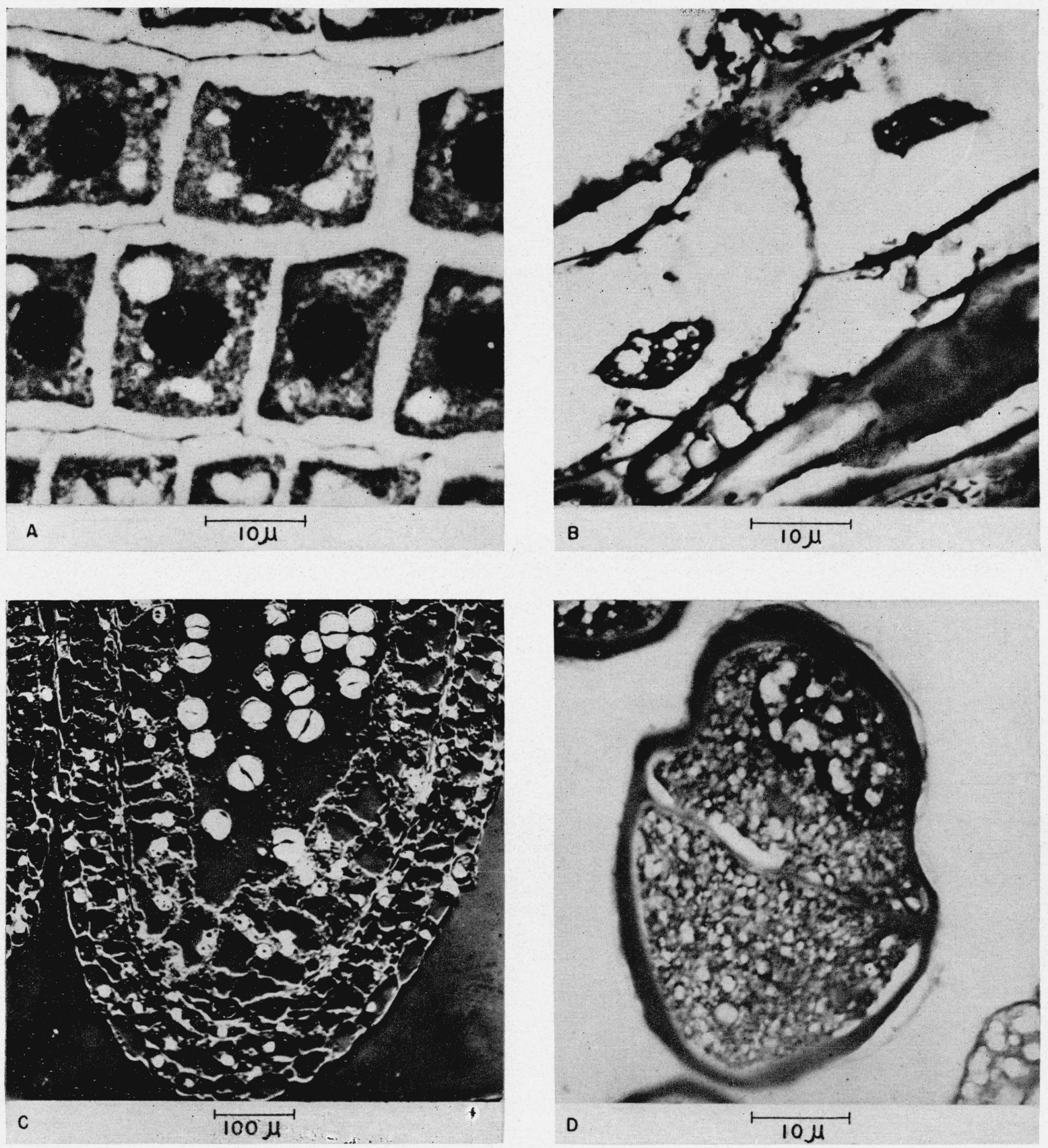

Figure 6.

$A$, Onion root tip, cells of meristem, fixed in boiling water (10 sec.). Electron micrograph, total magnification $\approx \times 1,500$ (electronic $\times 750$, optical $\times 2)$.

$C$, Lilium superbum anthers, longitudinal section through tip, fixed in acetic alcohol, stained in haematoxylin, shadowed with chromium (4:1). Photomicrograph, total magnification $\approx \times 120$.
$B$, Onion root tip, zone of elongation, fixed in Zirkle-Erlikis. Electron micrograph, total magnification $\approx \times 1,500$ (electronic $\times 750$, optical $\times 2$ ).

$D$, Lilium superbum microsporocytes, two-cell stage, fixed in acetic alcohol. Electron micrograph, total magnification $\approx \times 1,500$ (electronic $\times 750$, optical $\times 2)$. 


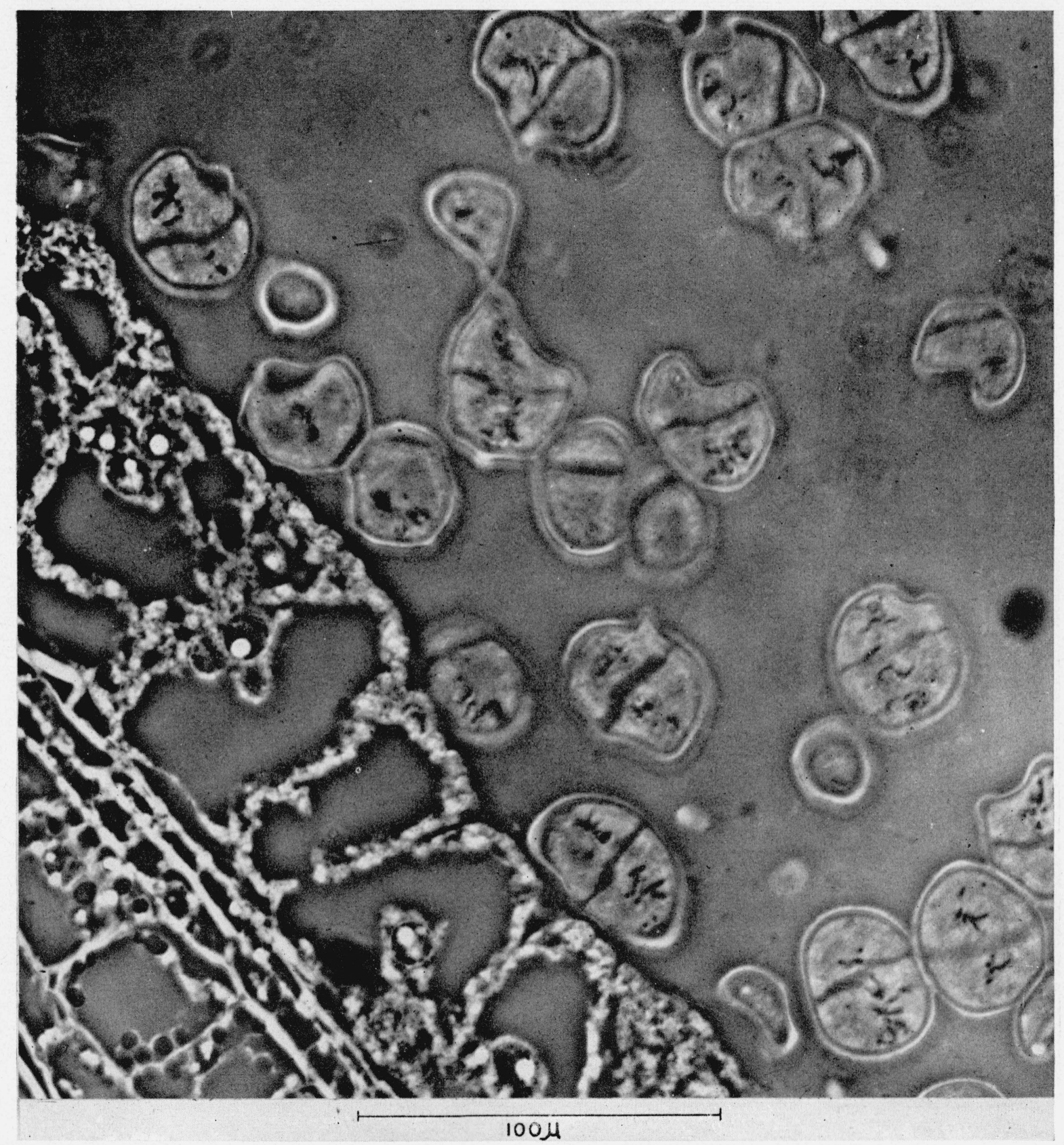

Figure 7. Lilium superbum microsporocytes, fixed in acetic alcohol.

Phase-contrast micrograph, total magnification $\approx \times 550$. 

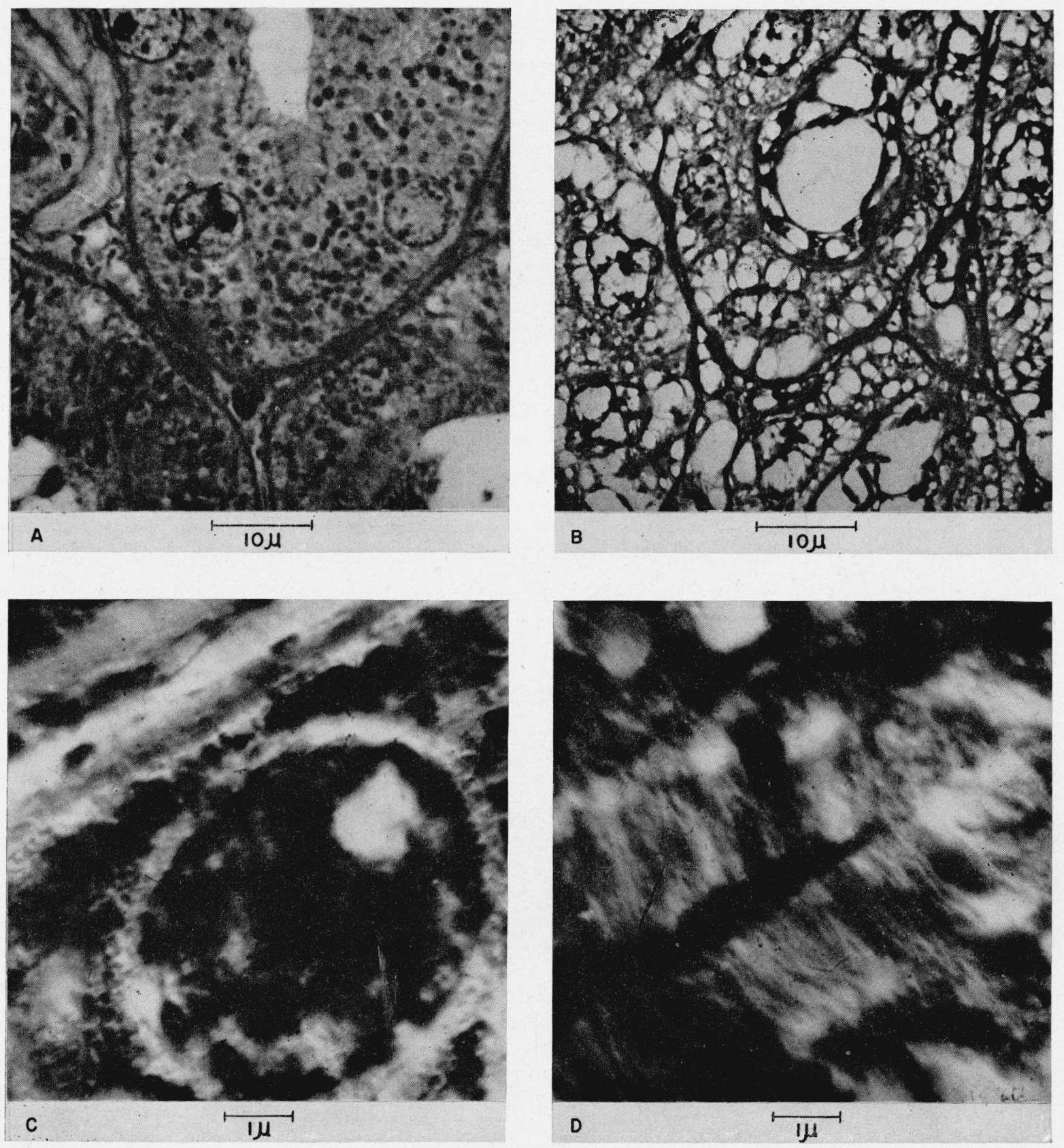

Figure 8.

$A$, Dog kidney, tubules and glomerulus, fixed in Zenker-formol. Electron micrograph, total magnification $\approx \times 1,500$ (electronic $\times 750$, optical $\times 2)$.

$C$, Dog kidney, section through tubule nucleus and basement membrane, fixed in Zenker-formol, chromium-shadowed (5:1). Electron micrograph, total magnification $\approx \times 10,400$ (electronic $\times 5,200$, optical $\times 2$ ).
$B$, Frog kidney, tubules, fixed in Bouin's. Electron micrograph, total magnification $\approx \times 1,500$ (electronic $\times 750$, optical $\times 2$ ).

$D$, Dog kidney, section through brush-border cilia of tubule lumen, fixed in Zenker-formol, chromium-shadowed (5:1). Electron micrograph, total magnification $\approx \times 10,400$ (electronic $\times 5,200$, optical $\times 2$ ). 


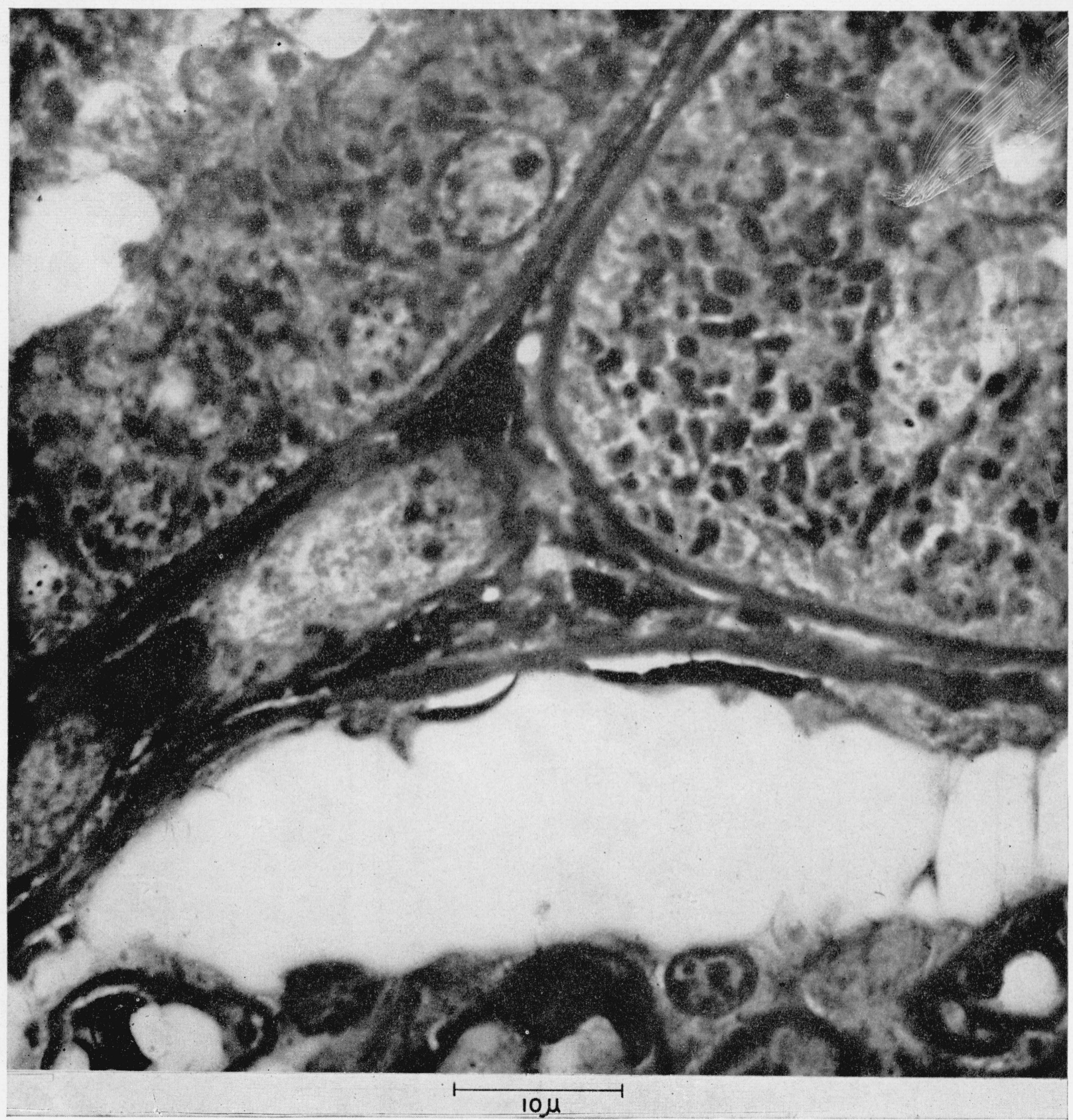

Figure 9. Dog kidney, section showing tubule and part of glomerulus, fixed in Zenker-formol.

Electron micrograph, total magnification $\approx \times 2,600$ (electronic $\times 750$, optical $\times 3.5$ ). 


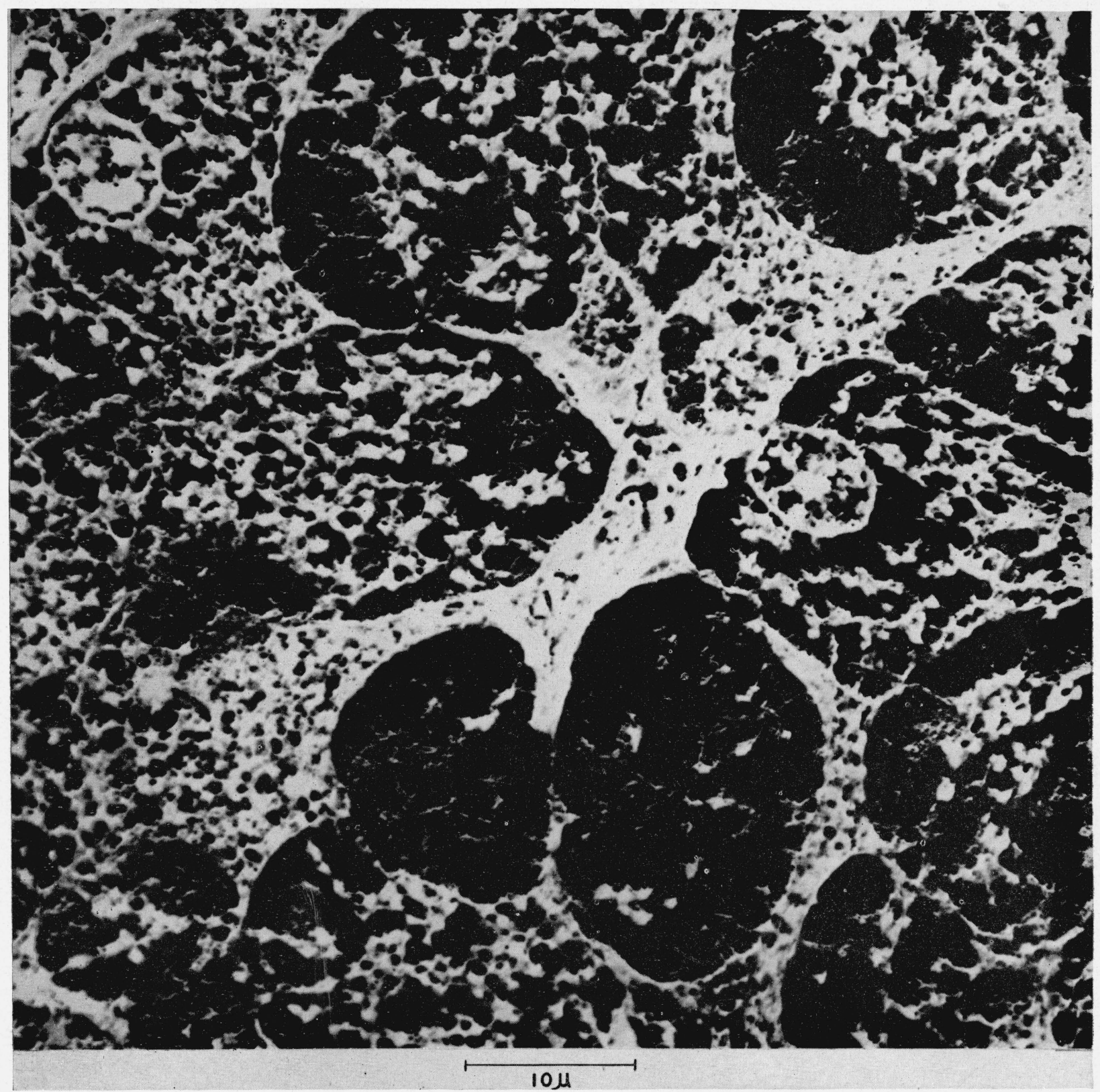

Figure 10. Frog liver, fixed in Bouin's, preshadowed with chromium (4:1).

Electron micrograph, total magnification $\approx \times 2,600$ (electronic $\times 750$, optical $\times 3.5$ ); 


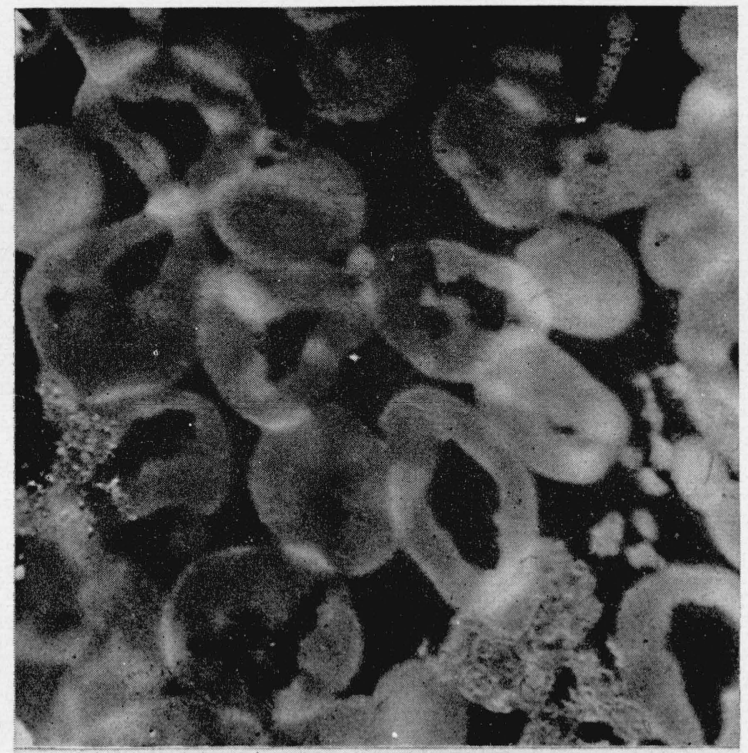

A

$+10 \mu$

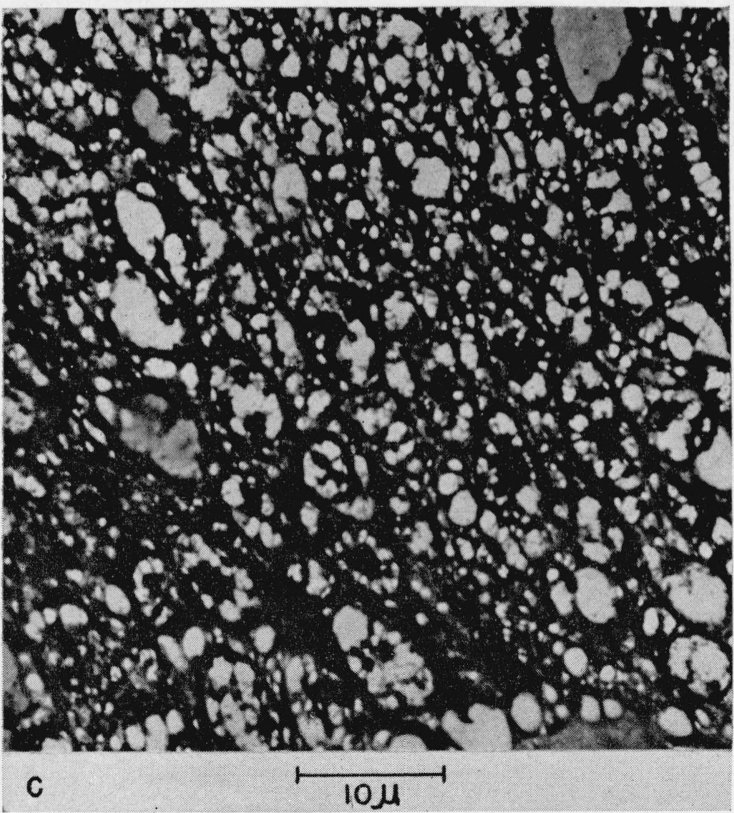

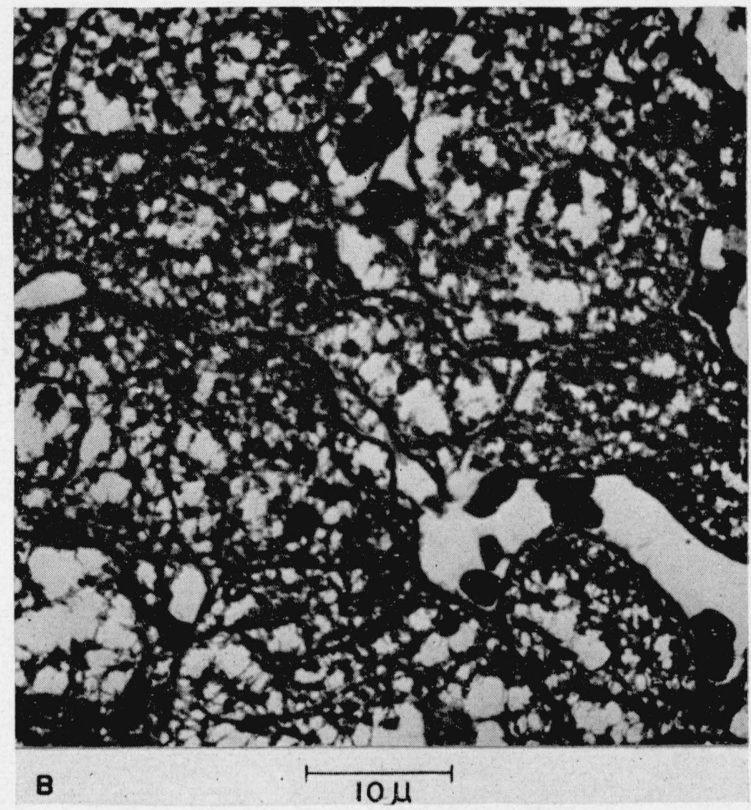

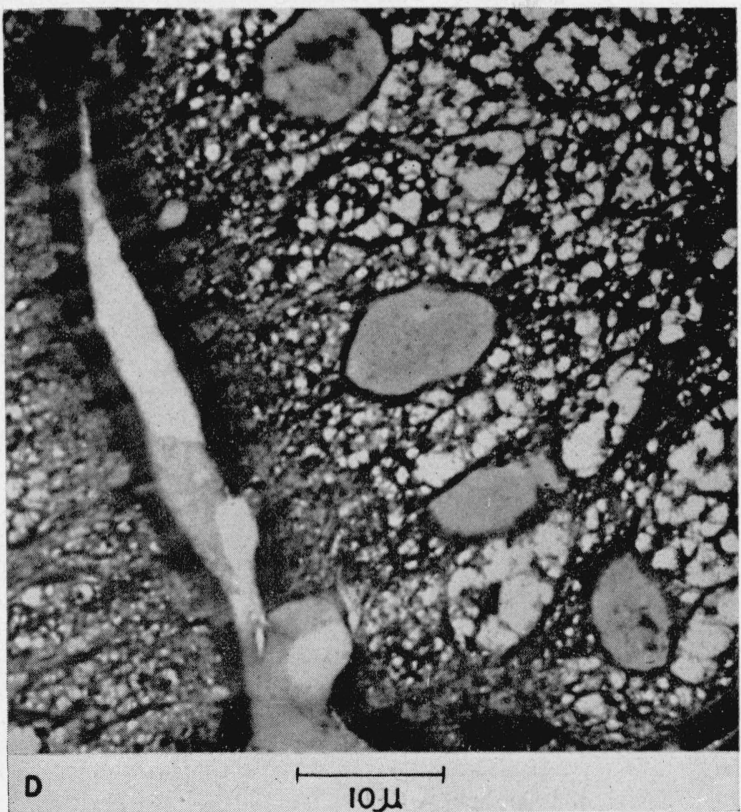

Figure 11.

$A$, Mouse red blood cells, in brain tissue, fixed in 10-percent formalin Electron micrograph, total magnification $\approx \times 1,500$ (electronic $\times 750$, optical $\times 2)$.

$C$, Frog's small intestine, section through interior of villus, fixed in Bouin's. Electron micrograph, total magnification $\approx \times 1,500$ (electronic $\times 750$, opticai $\times 2)$.
$B$, Mouse liver, fixed in Flemming's. Electron micrograph, total magnification $\approx \times 1,500$ (electronic $\times 750$, optical $\times 2$ ). (Tissue courtesy of $\mathrm{Na}$ tional Institutes of Health).

$D$, Frog's small intestine, section of villus, fixed in Bouin's. Electron micrograph, total magnification $\approx \times 1,500$ (electronic $\times 750$, optical $\times 2$ ). 


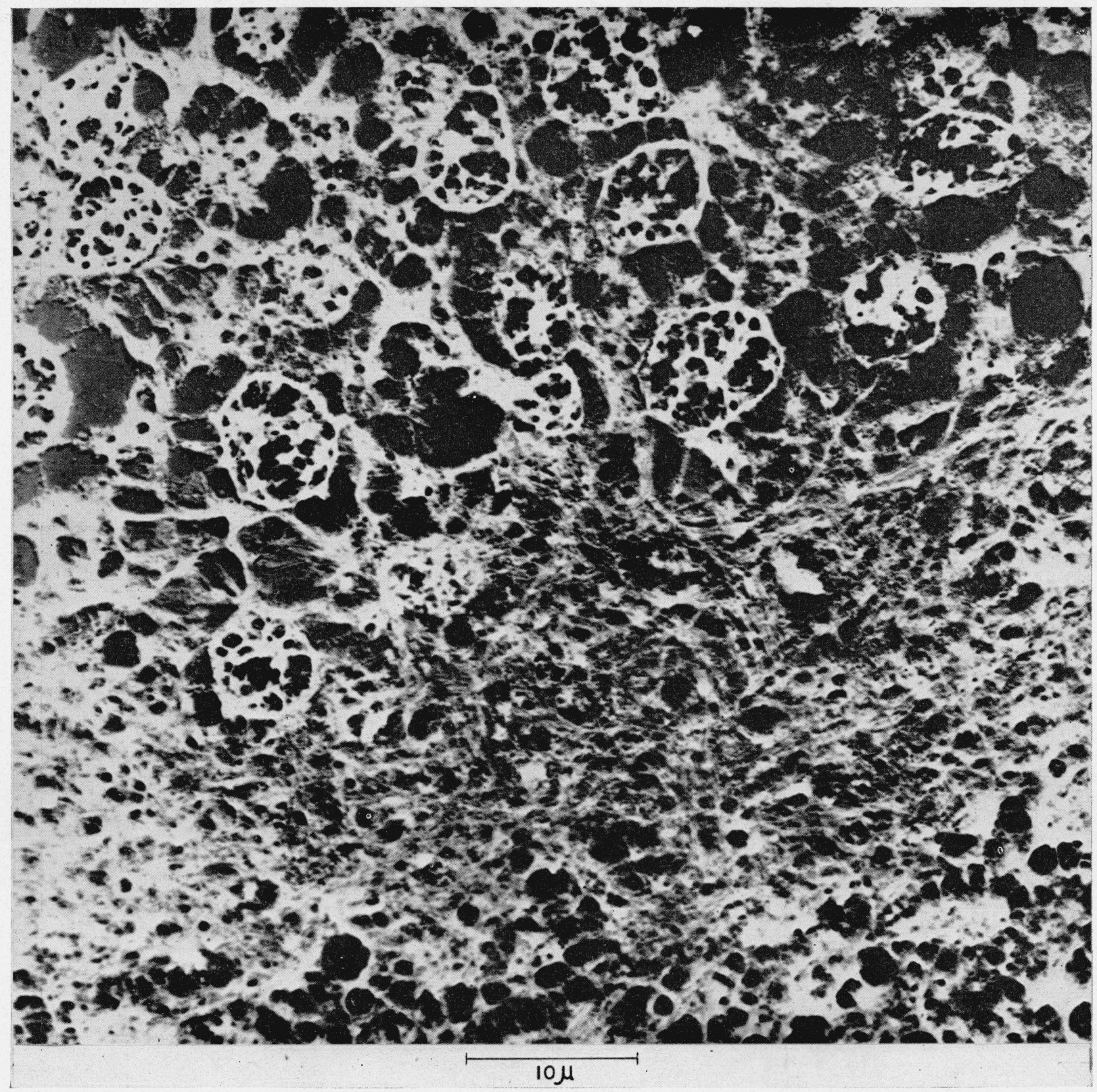

Figure 12. Frog's eye, section near area of rods and cones, fixed in Bouin's, chromium shadowed (4:1) Electron micrograph, total magniflcation $\approx \times 2,600$ (electronic $\times 750$, optical $\times 3.5$ ). 


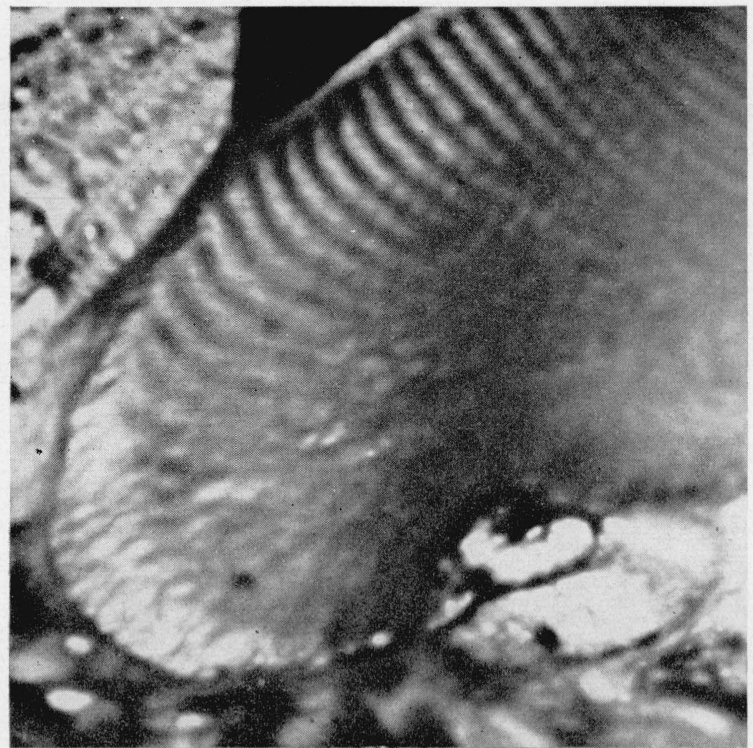

A

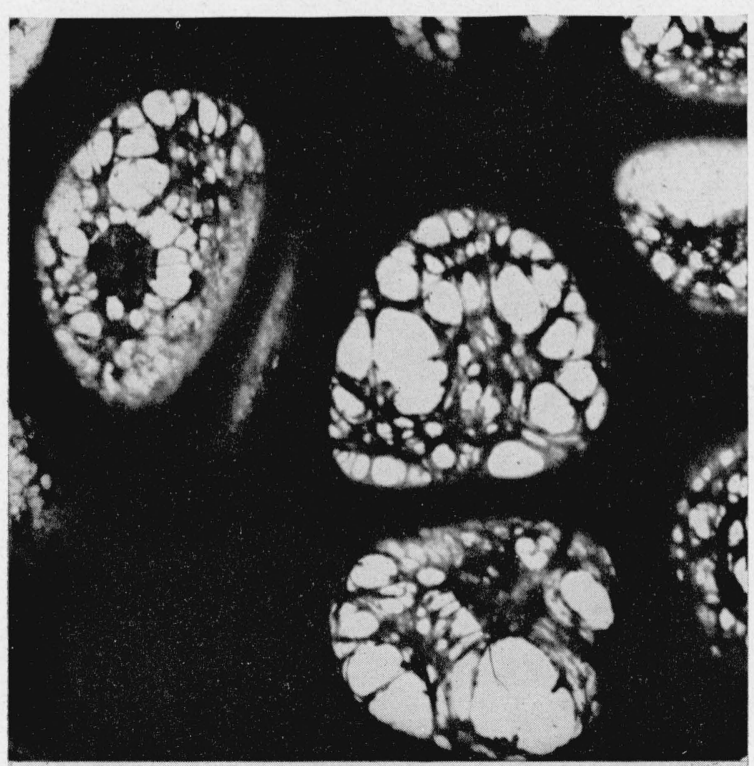

C
$10 \mu$

$10 \mu$

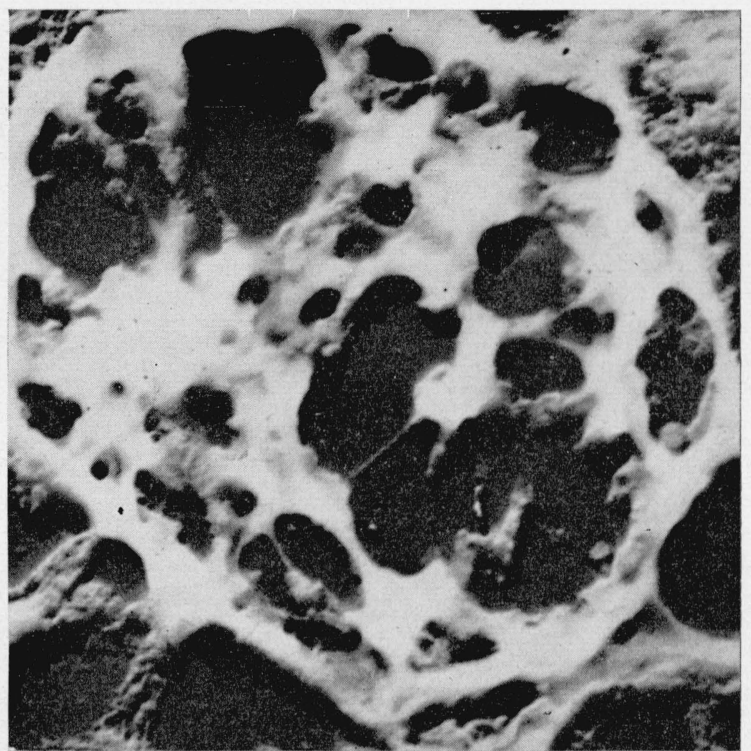

B

$\longmapsto$

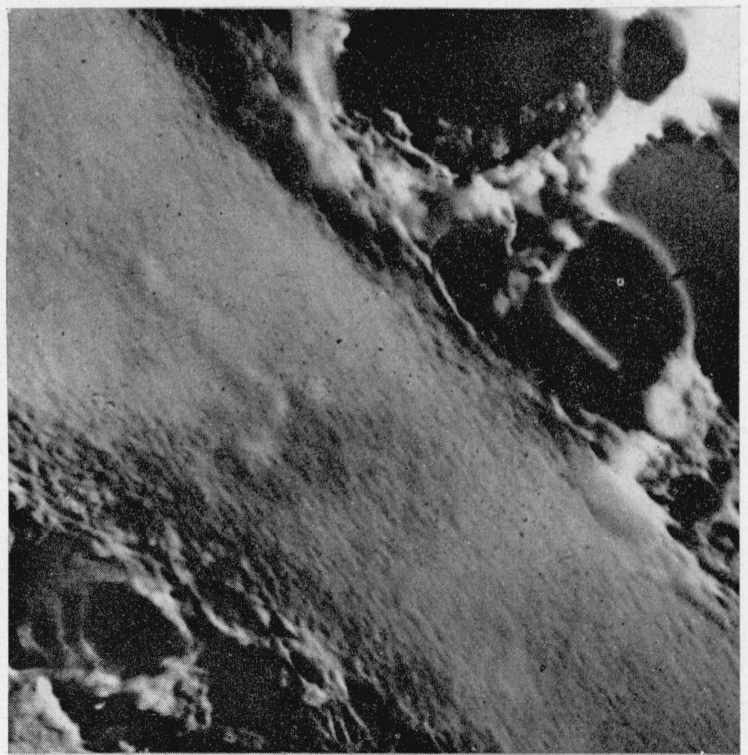

D

Figure 13.

$\boldsymbol{A}$, Frog's eve, section through muscle fiber, fixed in Bouin's. Electron micrograph, total magnification $\approx \times 1,500$ (electronic $\times 750$, optical $\times 2$ ).

$C$, Frog's eye, section through cartilage, fixed in Bouin's. Electron micrograph, total magnification $\approx \times 1,500$ (electronic $\times 750$, optical $\times 2$ ).
$B$, Frog's eye, section through nucleus of cell near rods and cones, fixed in Bouin's chromium-shadowed (4:1). Electron micrograph, total magnification $\approx \times 10,400$ (electronic $\times 5,200$, optical $\times 2$ ).

$D$, Frog's eye, section through cartilage, fixed in Bouin's, chromiumshadowed $(4: 1)$. Electron micrograph, total magnification $\approx \times 10,400$ (electronic $\times 5,200$, optical $\times 2$ ) 


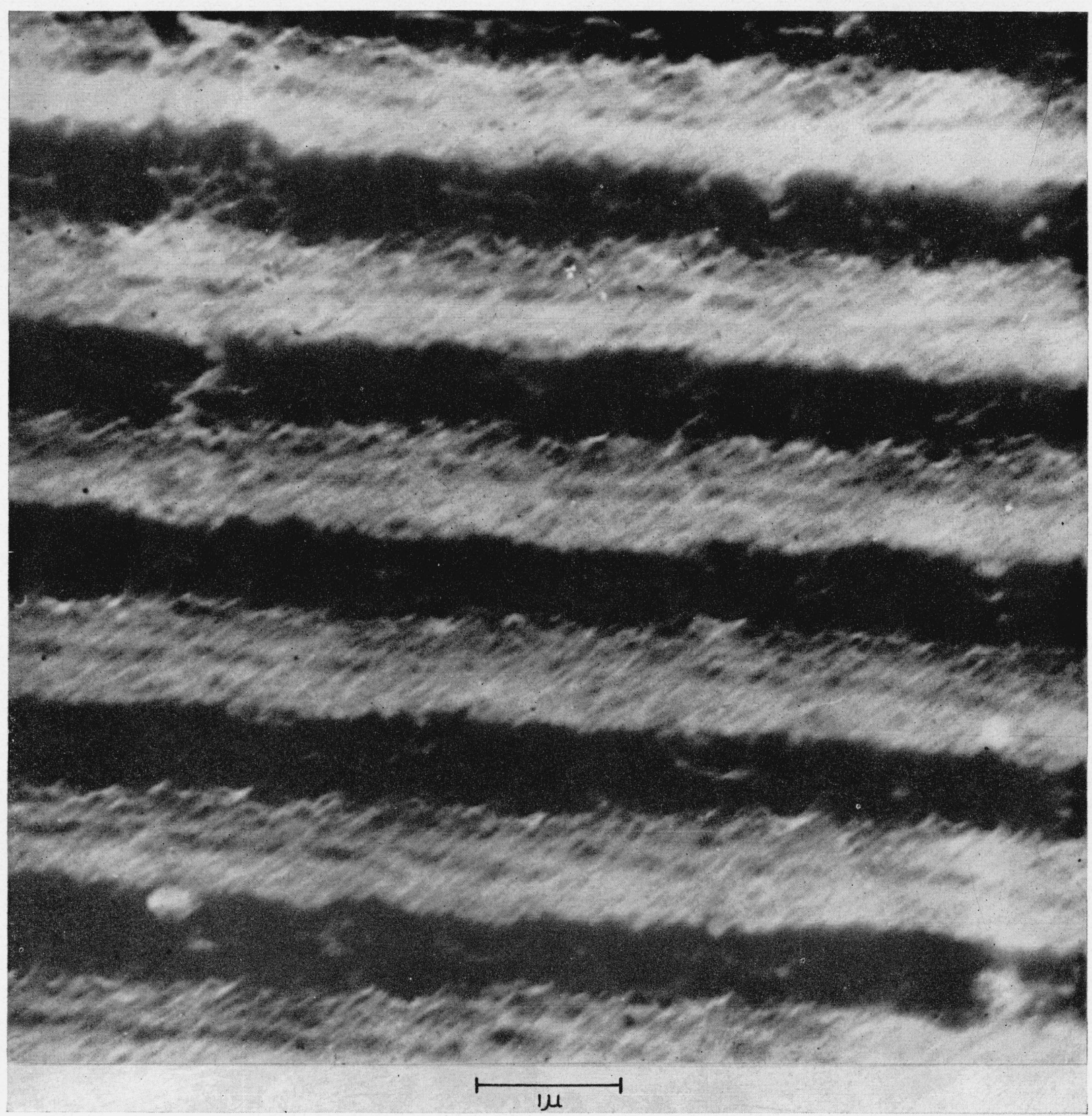

Figure 14. Frog's eye, detail of striated muscle fiber, fixed in Bouin's, chromium-shadowed (4:1). Electron micrograph, total magnification $\approx \times 22,000$ (electronic $\times 5,200$, optical $\times 4.3$ ). 


\section{References}

[1] M. von Ardenne, The wedge sectioning method for producing microtome cuts of less than $10^{-3} \mathrm{~mm}$ thickness for purposes of electron microscopy, Z. wiss. Mikroskop. 56, 8 (1939).

[2] M. von Ardenne, Electron microscopy of living tissue, Naturwissenschaften, 29, 521 (1941).

[3] W. T. Dempster, The mechanics of paraffin sectioning by the microtome, Anat. Rec. 84, 241 (1942).

[4] G. A. Richards, Jr., T. F. Anderson, and R. T. Hance, A microtome sectioning technique for electron microscopy illustrated with sections of striated muscle, Proc. Soc. Exptl. Biol. Med., 51, 148 (1942).

[5] G. A. Richards, Jr. and T. F. Anderson, Electron microscope studies of insect cuticle with a discussion of the application of electron optics to this problem, J. Morphol. \%1, 135 (1942).

[6] O. W. Richards, The effective use and proper care of the microtome (Spencer Lens Co., Buffalo, N. Y., 1942).

[7] H. C. O'Brien, Jr. and G. M. McKinley, New microtome and sectioning method for electron microscopy, Science 98, 455 (1943).

[8] F. Sjöstrand, Electron-microscopic examination of tissues, Nature 151, 725 (1943).

[9] O. W. Richards, Microtomy, Medical Physics, p. 750 to 759 (1944). (Edited by O. Glasser, Year Book Publishers, Chicago, Ill.)

[10] R. C. Williams and R. W. G. Wyckoff, The thickness of electron microscope objects, J. Applied Phys. 15, 712 (1944).

[11] R. C. Williams and R. W. G. Wyckoff, Electron shadow micrography of the tobacco mosaic virus protein, Science 101, 594 (1945).

[12] A. Claude and E. F. Fullam, The preparation of sections of guinea pig liver for electron microscopy, J. Exptl. Med. 83, 499 (1946).

[13] E. F. Fullam and A. E. Gessler, A high speed microtome for the electron microscope, Rev. Sci. Instruments 17, 23 (1946).

[14] A. E. Gessler and E. F. Fullam, Sectioning for the electron microscope accomplished by the high speed microtome, Am. J. Anat. 78, 245 (1946).

[15] M. C. Schuster, High speed microtoming, Interchem. Rev. 5, 31 (1946).

[16] R. C. Williams and R. W. G. Wyckoff, Applications of metallic shadow-casting to microscopy, J. Applied Phys. 17, 23 (1946).
[17] A. Claude, K. R. Porter, and E. G. Pickels, Electron microscope study of chicken tumor cells, Cancer Research $\boldsymbol{\gamma}, 421$ (1947).

[18] K. R. Porter and H. P. Thompson, Some morphological features of cultured rat sarcoma cells as revealed by the electron microscope, Cancer Research $\boldsymbol{7}$, 431 (1947).

[19] A. E. Gessler and C. E. Grey, Notes on the electron microscopy of tissue sections, submicroscopic spherical bodies in carcinoma, Exptl. Med. and Surgery V, 307 (1947).

[20] A. E. Gessler, C. E. Grey, and K. McCarty, Notes on the electron microscopy of tissue sections: submicroscopic spherical bodies in human carcinoma II, Exptl. Med. and Surgery VI, 329 (1946).

[21] A. E. Gessler, C. E. Grey, M. C. Schuster, J. J. Kelsch, and M. N. Richter, Notes on the electron microscopy of tissue sections, I. Normal tissue, II. Neoplastic, Cancer Research 8, 534 (1948).

[22] C. E. Grey, An electron microscope specimen punch, Rev. Sci. Instruments 19, 369 (1948).

[23] C. E. Grey, Microtome for electron microscopy, Interchem. Rev. \%, 26 (1948).

[24] C. E. Grey and J. J. Kelsch, Use of the electron microscope and high speed microtome in medicine, Exptl. Med. and Surgery VI, 368 (1948).

[25] B. Kisch, C. E. Grey, and J. J. Kelsch, Electron histology of the heart I, Exptl. Med. and Surgery VI, 346 (1948).

[26] D. C. Pease and R. F. Baker, Sectioning techniques for electron microscopy using a conventional microtome, Proc. Soc. Exptl. Biol. Med. 67, 470 (1948).

[27] M. Swerdlow and G. S. Seeman, A method for the electron microscopy of wool, J. Research NBS 41, 231 (1948) RP1921; Textile Res. J. XVIII, 536 (1948).

[28] R. F. Baker and D. C. Pease, Improved sectioning technique for electron microscopy, J. Applied Phys. 20, 480 (1949).

[29] D. C. Pease and R. F. Baker, Preliminary investigations of chromosomes and genes with the electron microscope, Science 109, 8 (1949).

[30] D. B. Scott and R. W. G. Wyckoff, Metal shadowing for the optical microscopy of certain tissues, Am. J. Clin. Path. 19, 63 (1949).

[31] R. C. Williams and R. C. Backus, Electron-micrographic structure of shadow-cast films and surfaces, J. Applied Phys. 20, 98 (1949).

Washington, June 3, 1949. 